\title{
EMERGÊNCIA DE Licania rigida BENTH (CHRYSOBALANACEAE) EM FUNÇÃO DO TRATAMENTO PRÉ-GERMINATIVO E DO TEMPO DE ARMAZENAMENTO
}

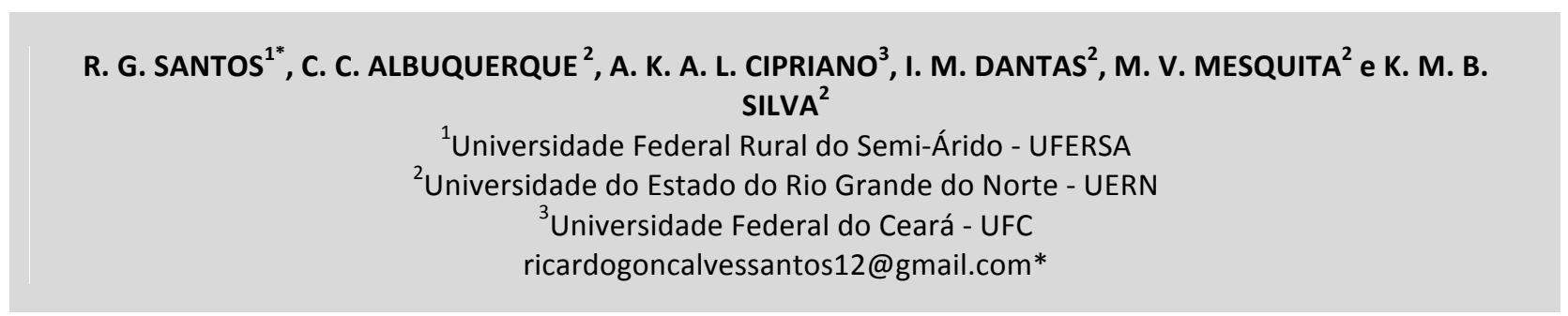

Submetido 18/02/2015 - Aceito 12/06/2017

DOI: $10.15628 /$ holos.2017.2773

\section{RESUMO}

Licania rigida é uma espécie arbórea, nativa da Caatinga, que contém uma semente rica em óleo, considerado fonte de matéria prima para diversos fins. Esse trabalho teve como objetivo avaliar o efeito de diferentes tratamentos pré-germinativos e o tempo de armazenamento em câmara fria sobre a emergência e viabilidade de sementes de $L$. rigida. Frutos recémcolhidos e armazenadas por 1 e 3 anos em câmara fria foram submetidas aos tratamentos: fruto íntegro controle, remoção do epicarpo, imersão em $\mathrm{H}_{2} \mathrm{SO}_{4}$ (98\%) por 10 minutos e embebição em água por 80 e 160 horas. Foram avaliados o percentual de emergência, o tempo médio de emergência e o índice de velocidade de emergência. $O$ delineamento experimental adotado foi o inteiramente casualizado em esquema fatorial $(5 \times 2)$ com quatro repetições de 20 sementes cada. As médias foram comparadas pelo Teste de Tukey. Os resultados mostraram que a remoção do epicarpo proporcionou o maior percentual e índice de velocidade de emergência para $L$. rigida, tanto nas sementes recém-colhidas quanto após um ano de armazenamento. As sementes perderam a viabilidade com o tempo de armazenamento em câmara fria, sendo que após três anos não houve emergência em nenhum tratamento.

PALAVRAS-CHAVE: Oiticica, propagação sexuada, sementes, vigor.

\section{EMERGENCY OF Licania rigida BENTH (CHRYSOBALANACEAE) UNDER EFFECT OF PRE-GERMINATION TREATMENT AND STORAGE TIME}

\begin{abstract}
Licania rigida is a tree native of Caatinga that contains a seed rich in oil, considered a source of raw material for various purposes. This study aimed to evaluate the effect of different pre-germination treatments and the duration of cold storage on emergence and viability of seeds of $L$. rigida. Freshly harvested fruits and stored for 1 and 3 years in cold chamber were treated as following: intact fruit - control, removal of the epicarp, immersion in $\mathrm{H} 2 \mathrm{SO} 4$ (98\%) for 10 minutes and soaking in water for 80 and 160 hours. We evaluated the percentage of
\end{abstract}

emergence, mean emergence time and emergence rate index. The experimental design was completely randomized in factorial scheme $(5 \times 2)$ with four replications of 20 seeds each. Data were compared by Tukey test. The results showed that removal of the epicarp provides greater percentage and emergence rate index for L. rigida in freshly harvested seeds, as well as in the seeds after one year of storage. The seeds lost viability with time of cold storage, and after three years there was no emergency between treatments.

KEYWORDS: Oiticica, sexual propagation, seeds, vigour. 


\section{INTRODUÇÃO}

A espécie Licania rigida Benth (Chrysobalanaceae), conhecida popularmente como oiticica, é uma espécie arbórea nativa de matas ciliares do Nordeste Brasileiro, apresenta copa densa e tronco curto, podendo atingir até $20 \mathrm{~m}$ de altura e possui folhas simples, coriáceas e esbranquiçadas na face inferior. A inflorescência é paniculada e o fruto é uma drupa oblonga ou arredondada (Duque, 2004; Diniz et al., 2008).

Esta planta é muito utilizada pela medicina popular em algumas regiões do Nordeste Brasileiro, sendo as folhas utilizadas principalmente no tratamento da diabetes e inflamações (Albuquerque et al., 2007). Além disso, o óleo de suas sementes é indicado como matéria prima para produção de sabão (Bezerra et al., 2009) e de biodiesel (Macedo et al., 2011). Também é empregado na indústria farmacêutica e cosmética e na produção de borrachas, lonas de freios, biolubrificantes, tintas e vernizes (Lima et al., 2012).

Assim como muitas espécies arbóreas da Caatinga, a oiticica oferece enorme potencial para utilização em arborização urbana, recuperação de áreas degradadas e exploração econômica de forma sustentável. No entanto, a carência de informações sobre a sua propagação e sobre o manejo de suas sementes pode ter limitado o seu uso. O conhecimento prévio da emergência das sementes desta espécie, bem como métodos que proporcionem uma germinação mais rápida e regular, além da viabilidade das sementes sob condições de armazenamento são necessários para uma efetiva contribuição para a conservação ambiental e exploração consciente dos recursos desta espécie.

O processo de germinação é definido por Marcos Filho (2005) como uma sequência complexa de reações bioquímicas pelas quais substâncias de reservas armazenadas no tecido de sustentação são desdobradas, transportadas e ressintetizadas no eixo embrionário. Este fenômeno ocorre quando as condições ambientais são propícias para ativá-lo. No entanto, é muito comum espécies vegetais apresentarem germinação lenta e desuniforme, mesmo quando expostas às condições ambientais favoráveis, o que, geralmente, apresenta-se como um dos principais problemas de produção de mudas em condições controladas.

O uso de tratamentos pré-germinativos como a escarificação mecânica e química, a embebição das sementes em água, tratamentos com altas temperaturas, entre outros, são bastantes empregados por tornar a germinação das sementes mais rápida e uniforme (Popinigis, 1985; Schmidt, 2002; Smiderle \& Sousa, 2003). Para a oiticica, quase não há informações na literatura sobre a sua propagação, tendo apenas informações cedidas por Duque (2004), que classificou a germinação das sementes como sendo tardia e desuniforme e, o registro do trabalho de Diniz et al. (2008), no qual foi relatado a influência da luz e temperatura na germinação de sementes desta espécie.

A manutenção da viabilidade por meio do armazenamento também é uma prática importante, principalmente em sementes nativas, em função da baixa longevidade natural dessas sementes. Oiticicas nativas não produzem todos os anos e as grandes produções aparecem uma vez em longos anos. Além de que, no mesmo bosque, algumas frutificam e outras não (Duque, 2004). Sendo assim, é de fundamental importância o conhecimento de condições adequadas de 
armazenamento dessas sementes, conservando sua viabilidade. Além disso, o armazenamento pode vir a ser útil para conservação de recursos genéticos da oiticica por meio de bancos de germoplasma.

Diante do exposto, este trabalho teve como objetivo avaliar o efeito de diferentes tratamentos pré-germinativos e o tempo de armazenamento em câmara fria sobre a emergência e viabilidade de sementes de L. rigida.

\section{METODOLOGIA}

As sementes de oiticica utilizadas neste trabalho foram coletadas de plantas matrizes na Floresta Nacional de Açu (FLONA - RN) em março de 2009. Após a coleta, as sementes foram selecionadas, descartando aquelas que apresentavam injúrias mecânicas, danos causados por pragas e defeitos de formação. Um lote das sementes foi utilizado para a montagem da primeira parte do experimento com as sementes recém-colhidas, em abril de 2009, e outros dois lotes foram armazenados em câmara fria (temperatura de $15 \pm 2^{\circ} \mathrm{C}$ e umidade relativa de $50 \%$ ) para uso em testes nos anos subsequentes, sendo um teste realizado em abril de 2010 e outro em abril de 2012.

A semeadura foi realizada em sacos de polietileno com capacidade para $1 \mathrm{~kg}$, contendo um substrato composto de areia lavada, argila e húmus (polifértil) na proporção de 1:1:1. O experimento foi conduzido em delineamento inteiramente casualizado e constituiu-se de cinco tratamentos prégerminativos (fruto íntegro - controle, remoção do epicarpo, imersão em $\mathrm{H}_{2} \mathrm{SO}_{4}$ (98\%) por 10 minutos e embebição em água por 80 e 160 h) testados em três épocas diferentes (quando colhidas e após 1 e 3 anos de armazenamento em câmara fria). Cada tratamento teve cinco repetições de 20 sementes. $O$ experimento foi conduzido em condições de casa de vegetação com $70 \%$ de redução de luminosidade e um sistema de rega por microaspersão (Rain Bird ${ }^{\circledR}$ ), o qual era acionado automaticamente duas vezes ao dia, com duração de 15 minutos cada irrigação (turno de rega 08h:00 e 16h:00).

Os dados foram coletados diariamente após a primeira emergência observada (critério de emergência: aparecimento da parte aérea da plântula na superfície do solo). As variáveis avaliadas foram porcentagem de emergência (\%E), tempo médio de emergência (TME) e índice de velocidade de emergência (IVE) das sementes.

A porcentagem de sementes emergidas foi estimada de acordo com Brasil (1992):

$\% \mathrm{E}=\frac{\mathrm{N}}{\mathrm{A}} \times 100$

em que,

$\% \mathrm{E}=$ porcentagem de emergência;

$\mathrm{N}$ = número de sementes emergidas;

$A=$ número total de sementes semeadas.

O TME foi estimado segundo Edmond e Drapala (1958):

$\mathrm{TME}=\frac{(\mathrm{N} 1 \mathrm{E} 1)+(\mathrm{N} 2 \mathrm{E} 2)+\cdots+(\mathrm{NnEn})}{\mathrm{E} 1+\mathrm{E} 2+\cdots+\mathrm{En}}$ 
onde,

TME = tempo médio de emergência (dias);

E1, E2, En = número de plântulas emergidas registradas na primeira, segunda, até a última contagem;

$\mathrm{N} 1, \mathrm{~N} 2, \mathrm{Nn}=$ número de dias da semeadura até a primeira, segunda e até a última contagem.

O IVE foi calculado pela fórmula proposta por Maguire (1962):

$\mathrm{IVE}=\frac{\mathrm{E} 1}{\mathrm{D} 1}+\frac{\mathrm{E} 2}{\mathrm{D} 2}+\cdots+\frac{\mathrm{En}}{\mathrm{Dn}}$

sendo,

IVE = índice de velocidade de emergência;

$\mathrm{E}_{1: n}=$ número de plântulas emergidas no dia $1, \ldots . ., \mathrm{n}$;

$D_{1: n}=$ dias para ocorrência da emergência.

As análises foram realizadas em esquema fatorial $(5 \times 2)$, empregando-se o tratamento prégerminativo como um fator e o período de armazenamento como outro fator. 0 terceiro período de armazenamento ( 3 anos) foi eliminado das análises, uma vez que nenhuma plântula emergiu. As médias dos tratamentos foram comparadas utilizando o teste de Tukey, com auxílio do software Estat (UNESP, 1994).

\section{RESULTADOS}

As análises estatísticas dos dados mostraram que os tratamentos pré-germinativos (TPG) e períodos de armazenamento (PA), bem como a interação destes fatores (TPG X PA), apresentaram influência significativa para o percentual, tempo médio e índice de velocidade de emergência (Tabela 1). No geral, as sementes com o epicarpo removido apresentaram melhores resultados (Tabelas 2, 3 e 4). As sementes diminuíram o vigor com o período de armazenamento, chegando a perder totalmente a viabilidade após 3 anos em câmara fria.

Tabela 1 - Quadrados médios oriundos da análise de variância. Sementes de Licania rigida Benth submetidas a diferentes tratamentos pré-germinativos e períodos de armazenamento em câmara fria.

\begin{tabular}{lcccc}
\hline \multirow{2}{*}{ Fatores de Variação } & & \multicolumn{3}{c}{ Quadrados Médios } \\
\cline { 3 - 5 } & $\mathrm{GL}$ & $\% \mathrm{E}$ & $\mathrm{TME}$ & IVE \\
\hline Tratamentos pré-germinativos (TPG) & 4 & $2453,047 * *$ & $3,803 * *$ & $0,1302 * *$ \\
Períodos de armazenamento (PA) & 1 & $240,953 * *$ & $7,982 * *$ & $0,0020 *$ \\
Interação entre fatores (TPG X TP) & 4 & $57,633 *$ & $6,610 * *$ & $0,0034 * *$ \\
Resíduo & 40 & 15,406 & 0,8261 & 0,0005 \\
\hline CV (\%) & & 16,166 & 14,290 & 2,699 \\
\hline
\end{tabular}

**Significativo ao nível de $1 \%$ de erro pelo teste $\mathrm{F},{ }^{*}$ Significativo ao nível de $5 \%$ de erro pelo teste $\mathrm{F}$. 
A remoção do epicarpo proporcionou, significativamente, o melhor percentual de emergência das sementes recém-colhidas (70\%), sendo $56 \%$ superior à testemunha (14\%). Do mesmo modo, com um ano de armazenamento, apesar do percentual de emergência ter diminuído para $52 \%$, este foi ainda, $47 \%$ maior que a testemunha (Tabela 2 ).

Tabela 2 - Percentual de emergência (\%E) de sementes de Licania rigida Benth submetidas a diferentes tratamentos pré-germinativos e períodos de armazenamento em câmara fria.

\begin{tabular}{lccc}
\hline \multirow{2}{*}{ Tratamentos } & \multicolumn{2}{c}{ Período de armazenamento } & \multirow{2}{*}{ Média } \\
\cline { 2 - 3 } & Recém-colhidas & 1 Ano & \\
\hline Testemunha & $14,00 \mathrm{bA}$ & $5,00 \mathrm{cB}$ & 9,5 \\
Epicarpo removido & $70,00 \mathrm{aA}$ & $52,00 \mathrm{aB}$ & 61,0 \\
10 min. em H $\mathrm{SO}_{4}$ & $13,00 \mathrm{bA}$ & $14,00 \mathrm{bA}$ & 13,5 \\
$80 \mathrm{~h}$ em $\mathrm{H}_{2} \mathrm{O}$ & $9,00 \mathrm{bA}$ & $6,00 \mathrm{cA}$ & 7,5 \\
$160 \mathrm{~h}$ em $\mathrm{H}_{2} \mathrm{O}$ & $5,00 \mathrm{bA}$ & $4,00 \mathrm{cA}$ & 4,5 \\
\hline Média & 22,20 & 16,20 & \\
\hline
\end{tabular}

Médias seguidas das mesmas letras minúscula nas colunas e maiúsculas nas linhas não diferem entre si pelo teste de Tukey $(P \leq 0,05)$.

As sementes tratadas com ácido sulfúrico por 10 minutos não diferiram do controle em nenhuma das variáveis avaliadas quando as sementes de oiticica eram recém-colhidas (Tabelas 2, 3 e 4). Porém, transcorrido um ano em câmara fria, estas apresentaram percentual e índice de velocidade de emergência significativamente maior que o controle (Tabelas 2 e 4).

Do mesmo modo, os tratamentos de pré-embebição em água por 80 e $160 \mathrm{~h}$ também não diferiram do controle quando as sementes eram recém-colhidas. No entanto, após um ano de armazenamento, a embebição em água proporcionou diferença significativa do tempo médio de emergência das sementes, sendo que foi reduzido de 65,5 para 25,2 dias quando se utilizou embebição por 80 h e de 40,2 para 24 dias quando as sementes embeberam água por 160 h (Tabela 3).

Tabela 3 - Tempo médio de emergência (TME em dias) de sementes de Licania rigida Benth submetida a diferentes tratamentos pré-germinativos e períodos de armazenamento em câmara fria.

\begin{tabular}{|c|c|c|c|}
\hline \multirow{2}{*}{ Tratamentos } & \multicolumn{2}{|c|}{ Período de armazenamento } & \multirow{2}{*}{ Média } \\
\hline & Recém-colhidas & 1 Ano & \\
\hline Testemunha & 46,766 abA & $63,250 \mathrm{aA}$ & 55,00 \\
\hline Epicarpo removido & $31,434 \mathrm{bA}$ & $32,500 \mathrm{bA}$ & 31,96 \\
\hline 10 min. em $\mathrm{H}_{2} \mathrm{SO}_{4}$ & $38,983 \mathrm{bA}$ & $40,412 \mathrm{abA}$ & 39,69 \\
\hline 80 h em $\mathrm{H}_{2} \mathrm{O}$ & 65,500 aA & $25,200 \mathrm{bB}$ & 45,35 \\
\hline $160 \mathrm{~h} \mathrm{em} \mathrm{H}_{2} \mathrm{O}$ & $40,200 \mathrm{abA}$ & $24,000 \mathrm{bB}$ & 32,10 \\
\hline Média & 44,576 & 37,072 & \\
\hline
\end{tabular}

Médias seguidas das mesmas letras minúscula nas colunas e maiúsculas nas linhas não diferem entre si pelo teste de Tukey $(P \leq 0,01)$. 
O índice de velocidade de emergência foi melhor nas sementes recém-colhidas com o epicarpo removido $(0,543)$, superando com significância os demais tratamentos. Embora este índice tenha caído para 0,426 após um ano de armazenamento em câmara fria, este ainda foi superior estatisticamente aos outros tratamentos pré-germinativos (Tabela 4).

Tabela 4 - Índice de velocidade de emergência (IVE) de sementes de Licania rigida Benth submetidas a diferentes tratamentos pré-germinativos e períodos de armazenamento em câmara fria.

\begin{tabular}{lccc}
\hline \multirow{2}{*}{ Tratamentos } & \multicolumn{2}{c}{ Período de armazenamento } & \multirow{2}{*}{ Média } \\
\cline { 2 - 3 } & Recém-colhidas & 1 Ano & \\
\hline Testemunha & $0,072 \mathrm{bA}$ & $0,017 \mathrm{cB}$ & 0,044 \\
Epicarpo removido & $0,543 \mathrm{aA}$ & $0,426 \mathrm{aB}$ & 0,484 \\
10 min. em $\mathrm{H}_{2} \mathrm{SO}_{4}$ & $0,073 \mathrm{bA}$ & $0,096 \mathrm{bA}$ & 0,084 \\
$80 \mathrm{~h} \mathrm{em} \mathrm{H}_{2} \mathrm{O}$ & $0,034 \mathrm{bA}$ & $0,048 \mathrm{bcA}$ & 0,041 \\
\hline $160 \mathrm{~h} \mathrm{em} \mathrm{H}_{2} \mathrm{O}$ & $0,022 \mathrm{bA}$ & $0,035 \mathrm{bcA}$ & 0,028 \\
\hline Média & 0,149 & 0,124 & \\
\hline
\end{tabular}

Médias seguidas das mesmas letras minúscula nas colunas e maiúsculas nas linhas não diferem entre si pelo teste de Tukey $(P \leq 0,05)$.

\section{DISCUSSÃO}

Os resultados demonstram que nas sementes de oiticica, o epicarpo dificulta o processo germinativo e, consequentemente, a emergência das sementes. Isto ocorre, provavelmente, porque essa camada que envolve a semente reduz a permeabilidade à água e a gases, necessários para influenciar o metabolismo da semente, ativando fisiologicamente a mesma, ou ainda, devido à presença de substâncias químicas inibidoras nestas camadas, como sugere Oliveira e Oliveira (2008). Estes autores, trabalhando com Schinopsis brasiliensis, conseguiram reduzir o tempo médio de germinação a praticamente à metade (de 19 para nove dias) e elevar a germinação de 4\% para 19\%, com a remoção das camadas externas (epicarpo e mesocarpo).

A camada externa pode atuar como uma barreira que dificulta a germinação da semente, porém, sob condições naturais adversas, essa barreira funciona como envoltório, servindo como um isolante que protege a semente do aquecimento e desidratação, podendo assim, proporcionar uma distribuição da germinação ao longo do tempo. Essa é uma estratégia evolutiva para que a espécie escape da seca, mantendo a semente viável até encontrar condições favoráveis ao processo germinativo e à sobrevivência das plântulas (Marcos Filho, 2005; Pellizzaro et al., 2011).

O uso do ácido sulfúrico neste trabalho não apresentou resultados satisfatórios. A ineficiência do tratamento químico com ácido sulfúrico concentrado pode ser devido a vários fatores, como o tempo de imersão usado ou o nível de sensibilidade do embrião a esse ácido. Portanto, muitas tentativas devem ser feitas a fim de determinar o tempo mais adequado para proporcionar maiores porcentagens e uniformidade de emergência e de vigor.

Apesar do ácido sulfúrico ser indicado por muitos autores ao se mostrar eficiente na superação de dormência de um grande número de espécies (Bianchetti et al., 1998; Rodrigues et al., 2008; Oliveira et al., 2009; Dutra et al., 2012), este deve sempre ser evitado quando houver outro 
método alternativo, pois além de ser uma técnica cara, pode oferecer risco a saúde das pessoas que manipulam.

No caso do tratamento das sementes com pré-embebição em água, apesar de ser um método bastante empregado para diminuir o tempo de emergência e proporcionar uma germinação mais homogenia (Ferreira \& Gentil, 2006; Teixeira et al., 2007), também não apresentou resposta satisfatória para a espécie em estudo, pois influenciou apenas na redução do tempo médio de emergência das sementes com um ano de armazenamento.

O sucesso no uso de métodos pré-germinativos em sementes de espécies nativas deve-se a vários fatores, entre eles, a facilidade de aplicação, viabilidade econômica, segurança no manuseio, etc... Para sementes de oiticica, o método de remoção do epicarpo além interferir positivamente no processo germinativo, apresenta-se, devido à facilidade de aplicação, como uma alternativa bastante viável e acessível.

Quanto ao armazenamento, Cavalcanti et al. (2006) afirmam que algumas sementes requerem um determinado período para que o embrião complete sua maturidade fisiológica, influenciando na germinação, como observado em sementes de Moringa oleifera (Oliveira et al., 2009) e Tabebuia serratifolia (Silva et al., 2011). No entanto, não é o caso para a espécie em estudo, já que o armazenamento prejudicou o vigor das sementes.

Por outro lado, vários autores encontraram resultados semelhantes aos observados neste trabalho, os quais relataram decréscimos na viabilidade e no vigor de sementes de diferentes espécies durante o período de armazenamento, a exemplo de Peltophorum dubium (Perez et al., 1999), Gossypium hirsutum (Freitas et al., 2000) e Tabebuia áurea (Oliveira et al., 2006). A redução na qualidade fisiológica das sementes com o incremento do tempo de armazenamento é atribuída, segundo Popinigis (1985) e Oliveira et al. (2009), às transformações degenerativas, que são características da deterioração das sementes.

A deterioração das sementes envolve uma série de alterações fisiológicas, bioquímicas e físicas que, eventualmente, causam a morte da semente. De acordo com Villela e Peres (2004), as alterações são progressivas e podem ser determinadas por diversos fatores como: genéticos, bióticos e abióticos, procedimentos de colheita, de secagem, de beneficiamento, de manuseio e de armazenamento.

Dentre as principais alterações envolvidas na deterioração das sementes, destacam-se o esgotamento das reservas alimentares, a alteração da composição química, como a oxidação dos lipídeos e a quebra parcial das proteínas, a alteração das membranas celulares, com redução da integridade, aumento da permeabilidade e desorganização, as alterações enzimáticas e as alterações de nucleotídeos (Popinigis, 1985; Villela \& Peres, 2004). Algumas dessas alterações ou várias delas em conjunto, associadas com a perda de vigor das sementes de oiticica, podem ter sido a causa da redução da emergência desta espécie com o aumento do período de armazenamento em câmara fria. 


\section{CONCLUSÕES}

Diante dos argumentos apresentados aqui, sugere-se que o epicarpo deve ser removido antes da semeadura das sementes de oiticica. A emergência desta espécie é melhor quando as sementes são recém-colhidas, portanto, o armazenamento por longos períodos deve ser evitado, uma vez que ocorre uma diminuição de sua viabilidade com o tempo de armazenamento, perdendo totalmente o poder germinativo após três anos em câmara fria.

\section{AGRADECIMENTOS}

Os autores agradecem ao Centro de Estudos e Pesquisas do Meio Ambiente e Desenvolvimento Regional do Semiárido (CEMAD) pelo apoio logístico e por colaborar com a realização das coletas em campo, ao Prof. Dr. Salvador Barros Torres, por disponibilizar a câmara fria para o armazenamento das sementes e ao Conselho Nacional de Desenvolvimento Científico e Tecnológico (CNPq) pela concessão de bolsas de Iniciação Científica.

\section{REFERÊNCIAS}

Albuquerque, U. P.; Monteiro, J. M.; Ramos, M. A. \& Amorim, E. L. C. (2007). Medicinal and magic plants from a public market in northeastern Brazil. Journal of Ethnopharmacology, Shannon, 110(1), 76-91. doi :10.1016/j.jep.2006.09.010

Bezerra, J. N. S.; Lopes, E. L.; Sousa, A. H.; Barbosa, F. G.; Neto, M. A. Constituintes químicos isolados das raízes de Licania rigida Benth. In: REUNIÃO ANUAL DA SOCIEDADE BRASILEIRA DE QUÍMICA, 32, 2009, Fortaleza. Anais... Fortaleza: SBQ, 2009.

Bianchetti, A.; Teixeira, C. A. D. \& Martins, E. P. (1998). Escarificação ácida para superar a dormência de sementes de pinho-cuiabano (Parkia multijuga Benth.). Revista Brasileira de Sementes, 20(1), 215-218.

Brasil - Ministério da Agricultura e Reforma Agrária. (1992). Regras para análise de sementes. Brasília: SNDA/DNDV/CLAV.

Cavalcanti, N. B.; Resende, G. M. \& Drumond, M. A. (2006). Período de dormência de sementes de imbuzeiro. Revista Caatinga, 19(2), 135-139.

Diniz, F. O.; Moreira, F. J. C.; Silva, F. D. B.; Filho, S. M. (2008). Influência da luz e temperatura na germinação de sementes de oiticica (Licania rigida Benth.). Revista Ciência Agronômica, 39(3), 476-480.

Duque, G. (2004). O Nordeste e as lavouras xerófilas. Fortaleza: Banco do Nordeste do Brasil.

Dutra, T. R.; Massad, M. D.; Sarmento, M. F. Q. \& Oliveira, J. C. (2012). Emergência e crescimento inicial da canafístula em diferentes substratos e métodos de superação de dormência. Revista Caatinga, 25(2), 65-71.

Edmond, J. B. \& Drapala, W. J. (1958). The effects of temperature, sand and soil, and acetone on germination of okra seeds. Proceedings of the American Society Horticultural Science, 71, 428-434. 
Ferreira, S. A. N. \& Gentil, D. F. O. (2006). Extração, embebição e germinação de sementes de tucumã (Astrocaryum aculeatum). Acta Amazonica, 36(2), 141-146.

Freitas, R. A.; Dias, D. C. F. S.; Cecon, P. R. \& Reis, M. S. (2000). Qualidade fisiológica e sanitária de sementes de algodão durante o armazenamento. Revista Brasileira de Sementes, 22(2), 94101.

Lima, M. J. S. L.; Candeia, R. A.; Conceição, M. M.; Silva, M. C. D.; Gondim, A. D. \& Souza, A. G. Avaliação térmica e espectroscópicos do biodiesel de oiticica. In: BRAZILIAN CONGRESS and PAN-AMERICAN CONGRESS ON THERMAL ANALYSIS AND COLORIMETRY, VIII, III, 2012, Campo do Jordão. Anais... Campos do Jordão: TACS, 2012.

Macedo, F. L.; Candeia, R. A.; Sales, L. L. M.; Dantas, M. B.; Souza, A. G. \& Conceição, M. M. (2011). Thermal characterization of oil and biodiesel from oiticica (Licania rigida Benth). Journal of Thermal Analysis and Calorimetry, 106(2), 531-534. doi: 10.1007/s10973-0111580-z

Maguire, J. D. (1962). Speed of germination aid in selection and evaluation for seedling emergence and vigor. Crop Science, 2(2), 176-177.

Marcos Filho, J. (2005). Fisiologia de sementes de plantas cultivadas. Piracicaba: FEALQ.

Oliveira, A. K. M.; Schleder, E. D. \& Favero, S. (2006). Caracterização morfológica, viabilidade e vigor de sementes de Tabebuia áurea (Silva Manso) Benth. \& Hook. f. ex. S. Moore. Revista Árvore, 30(1), 25-32.

Oliveira, L. M.; Ribeiro, M. C. C.; Maracajá, P. B. \& Carvalho, G. S. (2009). Qualidade fisiológica de sementes de moringa em função do tipo de embalagem, ambiente e tempo de armazenamento. Revista Caatinga, 22(4), 70-75.

Oliveira, M. C. P. \& Oliveira, G. J. (2008). Superação da dormência de sementes de Schinopsis brasiliensis. Ciência Rural, 38(1), 251-254.

Pellizzaro, K.; Mendes de Jesus, V. A.; Braccini, A. L.; Scapim, C. A. \& Viganó, J. (2011). Superação da dormência e influência do condicionamento osmótico em sementes de Pterogyne nitens Tul. (Fabaceae). Revista Caatinga, 24(3), 1-9.

Perez, S. C. J. G. A.; Fanti, S. C. \& Casali, C. A. (1999). Influência do armazenamento, substrato, envelhecimento precoce e profundidade de semeadura na germinação de canafístula. Bragantia, 58(1), 57-68.

Popinigis, F. (1985). Fisiologia da semente. Brasília: AGIPLAN.

Rodrigues, A. P. D. C.; Kohl, M. C.; Pedrinho, D. R.; Arias, E. R. A. \& Favero, S. (2008). Tratamentos para superar a dormência de sementes de Acacia mangium Willd. Acta Scientiarum Agronomy, 30(2), 279-283.

SCHMIDT, L. (2002). Guide to handling tropical and sub-tropical forest seed. Humlebaek: DFSC.

Silva, D. G.; Carvalho, M. L. M.; Nery, M. C.; Oliveira, L. M. \& Caldeira, C. M. (2011). Alterações fisiológicas e bioquímicas durante o armazenamento de sementes de Tabebuia serratifolia. Revista Cerne, 17(1), 1-7. doi: 10.1590/S0104-77602011000100001

Smiderle, O. J. \& sousa, R. C. P. (2003). Dormência em sementes de paricarana (Bowdichia virgilioides Kunth - Fabaceae - Papilionidae). Revista Brasileira de Sementes, 25(2), 48-52. 
Teixeira, M. T.; Vieira, H. D.; Teixeira, S. L. \& Silva, R. F. (2007). Influence of the desinfestation and osmotic conditioning on the germinating behavior of australian royal palm (Archontophoenix alexandrae) seeds. Revista Brasileira de Sementes, 29(1), 155-159.

UNESP - Universidade Estadual Paulista "Júlio de Mesquita Filho". (1994). ESTAT Versão 2.0. Jaboticabal: FCAV/UNESP.

Villela, F. A. \& Peres, W. B. (2004). Coleta, beneficiamento e armazenamento. In: Ferreira, G. A. \& Borghetti, F. (Ed.). Germinação: do básico ao aplicado (265-281). Porto Alegre: Artmed. 